\title{
Stanislavski na cena americana
}

\author{
INÁ CAMARGO COSTA
}

$\mathrm{N}$

OS ESTADOS Unidos, teatro sempre foi negócio sério, com o qual o Estado nunca teve qualquer compromisso, salvo pelo curto período (1935 a 1939) do Governo Roosevelt, quando uma pequena verba foi destinada a socorrer artistas desempregados, no âmbito da política do new deal.

Para se ter idéia do significado da palavra negócio, neste caso, basta dizer que, até 1914, a maior empresa dedicada à sua exploração, a dos irmãos Shubert, controlava 350 salas de espetáculo em todo o país, e que nos anos de 1920 (quando se consolidou a Broadway como o maior centro de produção de mediocridades) havia centenas de pequenas empresas produtoras sob o guarda-chuva da Shubert Teatrical Corporation. Um desdobramento necessário desta idéia: quando o cinema surgiu como produto mais lucrativo que o espetáculo teatral sob qualquer ponto de vista, esses produtores não hesitaram em transformar seus teatros em salas de exibição de filmes ou de espetáculos por sessões, na melhor das hipóteses alternando espetáculos de variedades (que podiam incluir até números de striptease) e projeções de filmes.

Num ambiente deste tipo, surge quase que naturalmente o star system, em que num primeiro momento grandes estrelas (homens ou mulheres) caem no gosto do público e se tornam chamarizes de bilheteria. Por causa delas os elencos se hierarquizam, atores se especializam e as próprias peças são escritas, desde logo oferecendo ao público o conhecido "mais do mesmo". As estrelas são tratadas com a máxima distinção, inclusive monetária - já que "valem mais" que os meros figurantes -, e em torno delas se desenvolve toda uma rede de interesses e grandes negócios liderada pela imprensa (jornais e publicações especializadas, que incluem livros e revistas).

As condições de trabalho, quando não chegam às raias da escravidão, envolvem de péssimos salários para quem não é estrela ao aterrorizante lema "o espetáculo tem que continuar", que despreza condições físicas ou psicológicas dos empregados (atores, técnicos, funcionários), ignora condições mínimas de palco (permitindo que artistas corram riscos de vida) e mesmo de sala - que podem ser inacreditáveis pulgueiros, para não dizer coisa mais pesada, pois põem em risco a saúde pública e assim por diante. Arte é uma palavra que passa muito longe do negócio, em larga medida herdada por Hollywood, que o desenvolveu amplamente e assumiu a liderança no setor (o teatro passou a funcionar de modo subordinado, sem nunca perder a condição de "laboratório artístico"), situação que persiste até hoje, pois por enquanto estamos falando de business. 
Não trataremos aqui das tentativas dos trabalhadores - dramaturgos e atores, principalmente - de enfrentar os patrões, pois isto nos levaria longe demais. Mas fique o registro da criação de inúmeras organizações sindicais que trataram de moderar o apetite dos investidores lutando por direitos autorais, no caso dos dramaturgos, e por mínimas condições de trabalho, no caso dos atores e técnicos.

Nosso assunto aqui tem a ver com a insatisfação de dramaturgos, atores e diretores quanto aos resultados de seu trabalho e com as condições de produção. Os dramaturgos, como é o caso de um O'Neill no início dos anos de 1920, porque

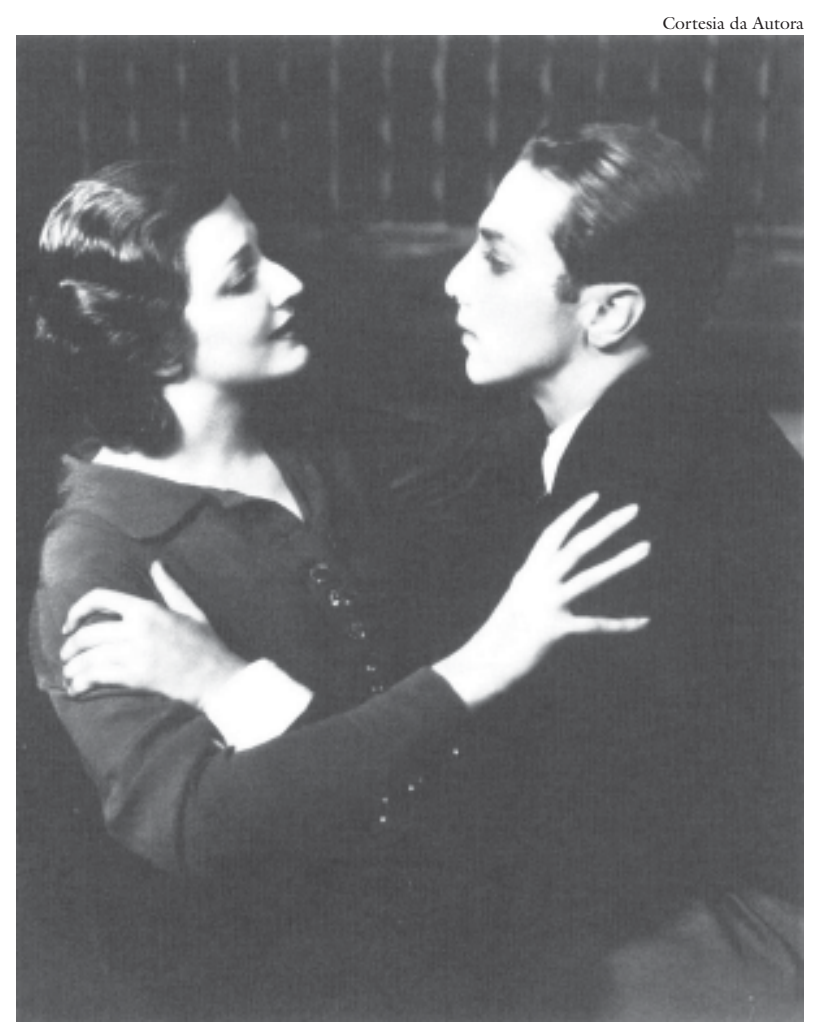

Stella e L. Adler em Success Story's, de J. H. Lawson. não admitiam a hipótese de ver seus textos interpretados por companhias como as então existentes, e os atores e/ou diretores, porque tinham conhecimento das possibilidades de atuar de modo diferente, e que já se desenvolviam na Europa, principalmente na Rússia. Desde 1905, quando o Teatro de Arte de Moscou (doravante referido como TAM) fez sua primeira excursão por Paris e Berlim, circulavam nos Estados Unidos notícias sobre "uma nova maneira de interpretar".

Para além de notícias regulares em jornais americanos e ingleses, em 1911 a publicação do livro de Gordon Craig ( $D a$ arte do teatro), com entusiásticos elogios a Stanislavski, estabelece um padrão de curiosidade sobre o trabalho do ator que só tende a se intensificar nos anos seguintes. Por sua vez, a Revolução de Outubro de 1917 amplia o raio da curiosidade para o teatro russo (e agora soviético) como um todo: em 1919 uma revista muito popular (Drama Magazine) publica um artigo que, sob o título $O$ teatro dramático russo, já estabelece até mesmo as diferenças entre os métodos de Stanislavski e Meierhold.

Finalmente, em 1922 o New York Times traz a notícia que todos os interessados em teatro esperavam: nova excursão do TAM, que agora inclui os Estados Unidos no roteiro. Falando de negócios, esta notícia marca o início de uma campanha publicitária que, por seu alcance e duração, só pode ser comparada às campanhas de lançamento de filmes de Hollywood. Por exemplo: o correspondente do Times em Berlim relata o sucesso da apresentação do Tzar Fiodor e 
adianta que não é preciso saber russo para entender tudo o que acontece em cena. As outras providências práticas incluíam ampla divulgação por meio de anúncios em todo tipo de veículo e sobretudo: venda antecipada de ingressos.

Mas, como estamos falando de uma companhia teatral da União Soviética, os empresários americanos acabaram contando com uma inesperada colaboração da direita para o sucesso da empreitada. Em Washington, a seção da American Defense Society promove uma manifestação de protesto, levantando a suspeita

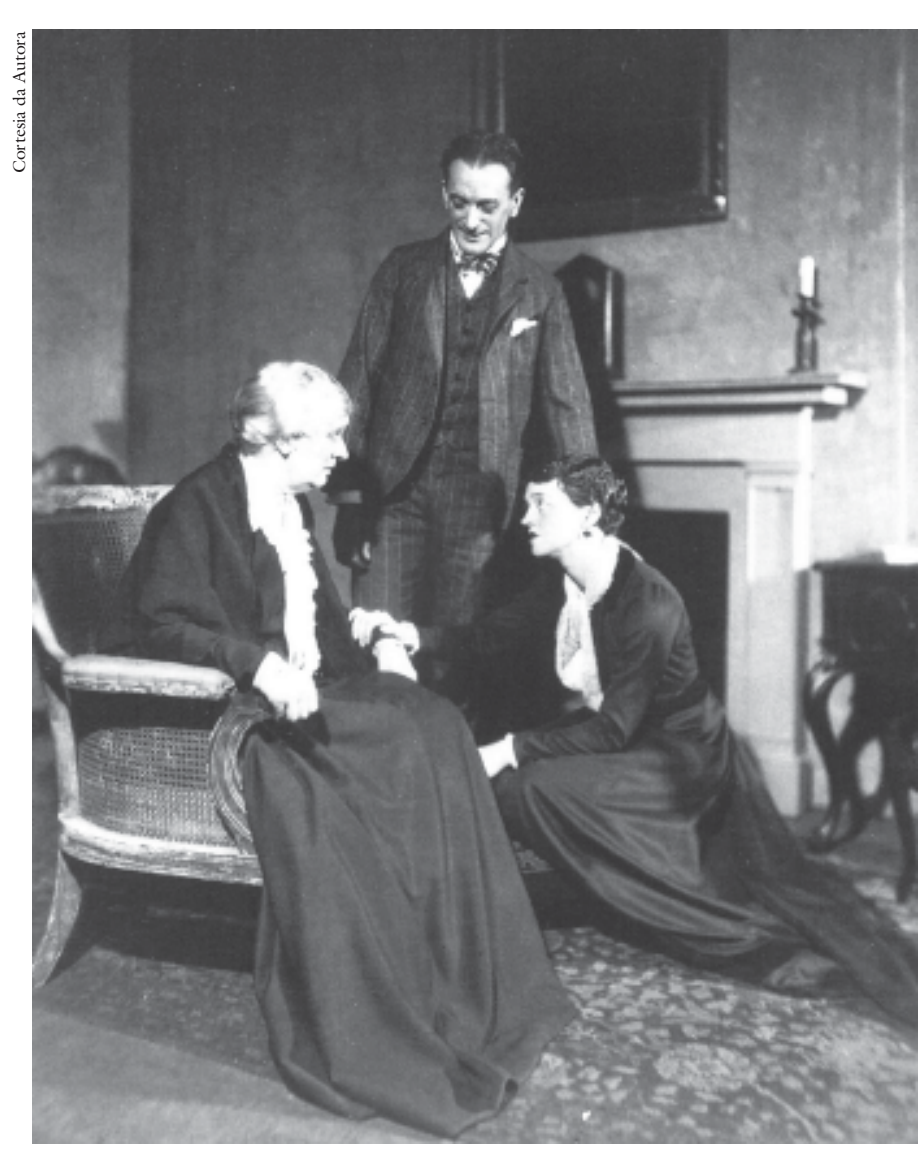

Eva Le Galliene (abaixada) em peça de S. Glaspell de 1930 de que o TAM poderia ser um bando de espiões soviéticos e que estavam angariando fundos para a causa do comunismo internacional. Com o New rork Times e o New Republic à frente, a grande imprensa (cujos interesses em comum com o negócio do teatro já foram apontados) partiu para a defesa da iniciativa, inclusive em editoriais, em nome da liberdade artística. Um dos grandes jornais publicou a declaração de Stanislavski em Paris: "Não temos ligação com o governo soviético. Só estamos interessados em arte. Nós trouxemos a nossa arte, não política" - o que, de fato, era verdade.

O resultado da campanha ultrapassou as previsões mais otimistas. O TAM estreou em Nova York, em janeiro de 1923, com a casa lotada, e uma temporada prevista para dois meses foi esticada para três, com direito a novo contrato para novembro daquele mesmo ano e, desta vez, com o seguinte roteiro: nove semanas em Nova York, três em Chicago, uma nas cidades de Boston, Filadélfia, Washington, Pittsburgh, Brooklin, Detroit e Cleveland; três dias em Hartford e também em New Haven. Esta temporada se encerrou em maio de 1924.

A imprensa deu conta de registrar as mais importantes unanimidades americanas a respeito dos espetáculos do TAM: a barreira lingüística não prejudicou a fruição dos espetáculos porque se tratava de entender e sentir o que acontecia 
em cena; no palco assistia-se a uma fatia de vida e não a uma peça de teatro; os atores vivem seus papéis, não os interpretam; e, independentemente de haver hierarquização dos personagens, todos os atores têm igual importância na realização do espetáculo, o que resulta do trabalho conjunto (ensemble), coisa jamais vista nos Estados Unidos.

Como não podia deixar de ser, os maiores interessados em ver os espetáculos do TAM eram os próprios atores das inúmeras companhias. Por meio da Actors Equity (uma organização sindical) obtiveram para a classe a realização de sessões especiais que sempre tiveram lotação esgotada. John Barrymore (da dinastia dos Drew), um dos maiores atores do star system, declarou que aqueles espetáculos foram a melhor coisa que se viu na vida em matéria de teatro.

Uma das atrizes do elenco, Maria Uspenskaia, resolveu permanecer nos Estados Unidos e, junto com Richard Boleslavski, veterano do TAM que se encontrava no país, acabaram sendo contratados para dar aulas de interpretação num empreendimento (igualmente business) que se chamou "American Laboratory Theatre" iniciado já no ano de 1924. Na verdade, Boleslavski cuidava da teoria que expunha em palestras e Uspenskaia cuidava da prática em suas aulas.

Assim como esses dois, alguns outros veteranos do TAM vieram para os Estados Unidos ao longo dos anos de 1920 e início dos anos de 1930, onde se estabeleceram e assumiram a missão de transmitir o legado de Stanislavski, dos quais vale mencionar Maria e Ivan Lazariev, Leo e Barbara Bulgakov e, finalmente, Mikhail Tchékhov, sobrinho do dramaturgo, que passou primeiro pela Inglaterra, onde fundou um estúdio, e só chegou em Nova York no final dos anos de 1930. Ele foi professor do nosso conhecido Yul Brynner.

Por aquilo que já ficou dito, obviamente o "sistema" de Stanislavski não podia funcionar no star system americano e a questão do repertório (Ibsen, Gorki, Tchékhov) talvez nem seja a mais determinante. Mais que difícil, impossível para um empresário teatral seria aceitar que seus elencos se organizassem como ensembles para ensaiar e apresentar as peças, quaisquer que fossem. Primeiro, pelo tempo necessário aos ensaios (enquanto pelo padrão Broadway uma peça podia no máximo consumir quatro semanas em ensaios, pelo padrão Stanislavski podia requerer mais de quatro meses) e, em segundo lugar, pela democratização do trabalho conjunto que implicava necessariamente a supressão das estrelas (as "galinhas dos ovos de ouro" do sistema).

Essa é a razão, por assim dizer, endógena (ao ambiente teatral) por que, desde o início, Stanislavski foi um assunto e um interesse da esquerda americana, ainda que sua introdução no país tenha sido uma operação estritamente de mercado. A outra razão do interesse por este mestre do teatro está ligada a seu vínculo natural com os problemas sociais e políticos do país, que também se traduzem em textos teatrais e se traduziram em experimentos e iniciativas que se contrapunham ao star system. 


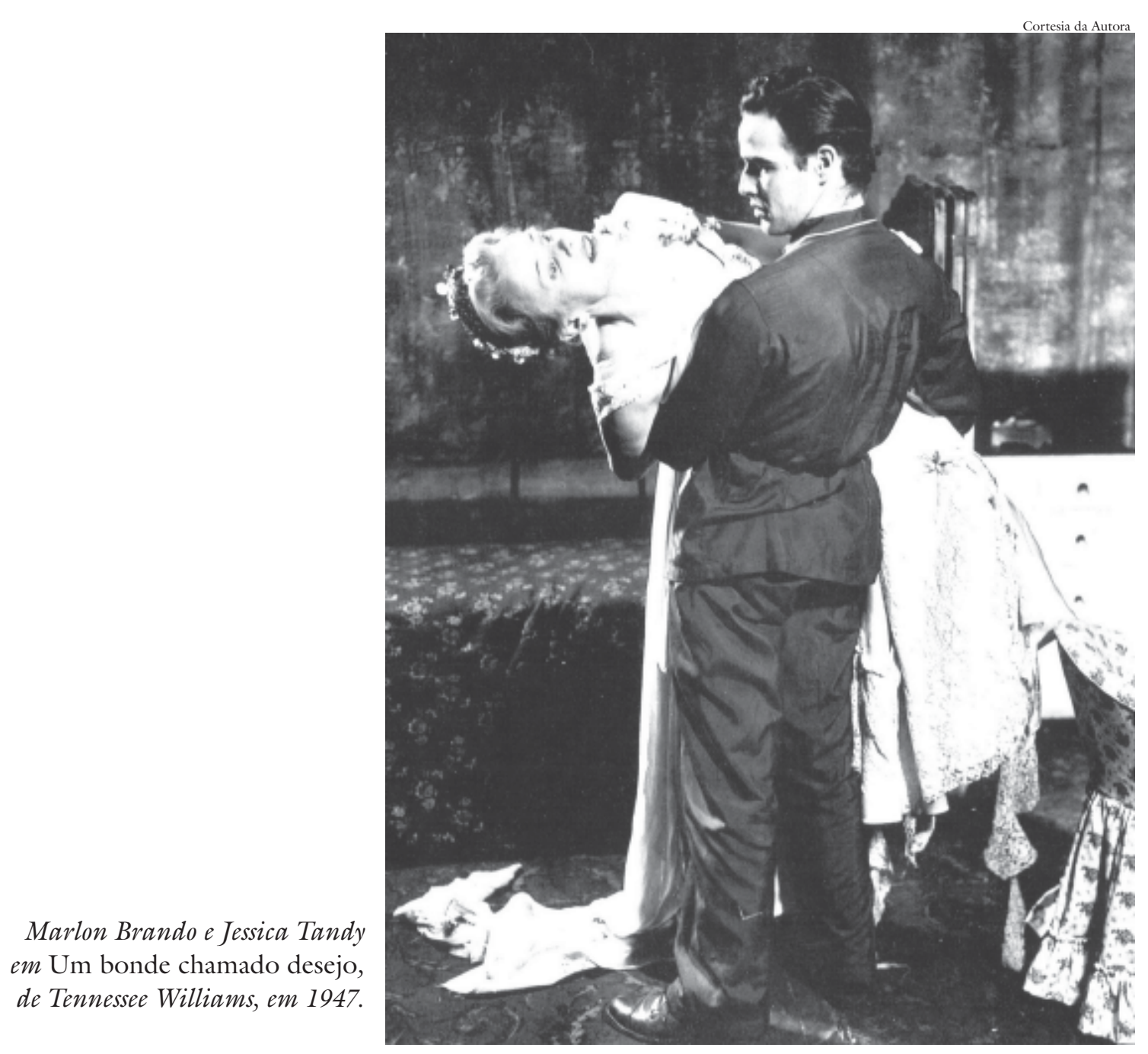

O próprio American Laboratory Theatre é um exemplo disso e na mesma conjuntura apareceram duas iniciativas complementares ou mesmo vinculadas a ele. A primeira foi a criação do Civic Repertory Theatre em 1926 por Eva Le Gallienne, proveniente de família com tradição no show business, que incorporou a seu elenco a atriz do TAM, Alla Nazimova, e se dedicou a encenar Ibsen e Tchékhov segundo o padrão stanislavskiano. A segunda foi o Group Theatre, criado por profissionais do Guild Theatre (a mais avançada, moderna e respeitada companhia do star system) que foram alunos de Boleslavski e Uspenskaia no American Laboratory Theatre: Harold Clurman, Cheryl Crawford e Lee Strasberg. Foi também no American Laboratory Theatre que Harold Clurman conheceu Stella Adler, com quem mais tarde se casaria (na verdade reencontrou a atriz que na infância vira no teatro ídiche de Nova York).

O Group Theatre também merece uma história à parte (já existe razoável bibliografia a respeito), mas, para o que nos interessa agora, é preciso registrar que com ele pelo menos duas coisas ficaram demonstradas na cena americana. A 
primeira é obviamente a viabilidade, o interesse e a superioridade do trabalho teatral realizado por um ensemble. E a segunda foi a consolidação da dramaturgia séria americana, fenômeno que só aconteceu no século XX e teve como pioneiros na primeira década do século Elmer Rice e Eugene O’Neill.

O capítulo seguinte desta história tem como protagonista Lee Strasberg, o primeiro diretor do Group Theatre e que passou a ser conhecido como o responsável pelos desenvolvimentos propriamente americanos da teoria stanislavskiana, sobretudo nos anos de 1940, quando se tornou o maior mestre de atores no Actors' Studio e "senhor" do "Método". Sua fama já vinha de algumas das experiências no Group e, descontando ao menos em parte a mitologia criada em torno de sua figura, vale a pena reconstituir em linhas gerais o tema básico da "questão do método" que nos anos de 1950 envolveu a quase totalidade da classe teatral - e, a esta altura, a cinematográfica também.

Por certo houve disputas diversas para se definir quem seria o legítimo “herdeiro" de Stanislavski nos Estados Unidos já no século XXI; não pode mais ser esse o móvel da curiosidade de quem vive num país como o nosso, que só acompanhou tudo isso muito à distância e sobretudo em seus aspectos inteiramente transformados em folclore (pelas "publicações especializadas" do próprio star system).

De qualquer modo, o que poderíamos chamar de disputa entre Lee Strasberg e Stella Adler tem alguma coisa produtiva que ainda hoje pode ser de interesse para nós. Tendo entrado para o Group em 1930 (ele fora fundado em 1929), ela estreou com seu irmão Luther numa peça de John Howard Lawson, dirigida por Lee Strasberg, Success story. O resultado foi tão notável que a peça e sua atuação memorável, especialmente na cena final, se tornaram cult (para usar o nosso jargão recente). Sobretudo atores se empenhavam em vê-la e consta que John Barrymore ia ao teatro para estudar seu trabalho. Noel Coward teria visto a peça por sete vezes!

O problema apareceu em seguida, quando a atriz se sentiu tolhida pelo método de trabalho de Strasberg que, àquela altura, era centrado na exploração da memória afetiva do ator. A atriz afastou-se do grupo, viajou à Europa e em Paris conheceu ninguém menos que o próprio Stanislavski. Em uma longa conversa com ele, concluiu que o seu problema não era com o sistema do mestre russo, mas sim com a maneira como Strasberg o desenvolvera. Voltando ao Group, começou a dar aulas também, tratando de dar ênfase a aspectos com que Strasberg não trabalhava, sobretudo o papel da imaginação do ator em seu trabalho. E, liberta das amarras da "memória afetiva", voltou a encontrar prazer em atuar, criando em 1935 uma Bessie (personagem de Awake and sing, de Clifford Odets, dirigida por Harold Clurman) que também ficou na história.

O Actors' Studio foi fundado em 1947 por Cheryl Crawford, Elia Kazan e Robert Lewis. Estes dois começaram como estudantes do Group Theatre, mas 
Bobby Lewis já fizera parte do elenco do Civic Repertory Theatre (como, aliás, inúmeros outros membros da primeira turma do Group). Com a saída deste em 1948, Lee Strasberg foi convidado a participar do empreendimento e ali encontrou finalmente o lugar onde levaria suas idéias sobre formação do ator às últimas conseqüências. A partir de 1951 tornou-se o diretor artístico do Studio. Quanto a Stella Adler, com o encerramento em 1939 das atividades do Group, passou a lecionar na Erwin Piscator's Dramatic Workshop da New School for Social Research. Mais tarde, em 1949, cria o Stella Adler Acting Studio e, desde então, nunca mais parou de dar aulas. (Para quem gosta de histórias fechadas, Strasberg morreu em 1982 e Stella Adler em 1992.)

Com essas informações, estão identificados os principais representantes americanos da Escola de Stanislavski nos Estados Unidos. O detalhe importante é que ambos são provenientes da vida cultural judaica em Nova York.

Nos anos de 1930, a cultura relevante nos Estados Unidos era de esquerda e isso aparecia de modo mais claro no teatro. Foi esta situação que permitiu aos adeptos de Stanislavski implantarem no país uma cultura teatral infinitamente mais exigente em termos artísticos do que o establishment jamais fora capaz de produzir. As condições materiais foram criadas pelo crack da Bolsa em 1929, que fez o dinheiro das produções da Broadway virar pó e levou os "grandes produtores" a baterem em retirada. Mas com os ganhos da Segunda Guerra, eles se realinharam e rapidamente retomaram os seus lugares e, sobretudo, o controle ideológico do debate sobre o teatro.

Assim, ao mesmo tempo em que grandes acontecimentos teatrais, amplos sucessos de público e bilheteria, eram promovidos pela esquerda, como a revelação de Tennessee Williams em 1947 com Um bonde chamado desejo e a de Marlon Brando como um dos maiores atores de sua geração, ou a de Arthur Miller em 1949 com A morte de um caixeiro viajante, eles iam sendo neutralizados pelo establishment com o crescente processo de discussão e, finalmente, a desqualificação do "método". Esta é uma história que ainda não foi devidamente examinada nem pelos próprios estudiosos do teatro americano moderno, mas existem vários registros das tentativas, por parte de seus adeptos, de ao menos colocar a discussão nos seus devidos termos. Os livros de Lee Strasberg ( Um sonho de paixão) e Robert Lewis (Método ou loucura), ambos publicados no Brasil, são importantes capítulos dessa verdadeira guerra travada na cena americana, sobretudo a partir dos anos de 1950. Mais recentemente, editoras brasileiras parecem ter descoberto também a contribuição de Stella Adler, mas estamos muito longe de dispor de um quadro mínimo do que se precisa saber em língua portuguesa.

Basicamente, Lewis e Strasberg nos ajudam a entender a preocupação central de Stanislavski com a formação exigente do ator. Stella Adler, além disso, tem a preocupação, que também era de Stanislavski, com o estudo dos principais dramaturgos do final do século XIX que, em suas palavras, ainda são tão mal 
lidos, mal compreendidos e mal encenados no teatro americano. Se ela estiver certa, a contra-revolução promovida pelo establishment foi vitoriosa em todas as frentes. E a principal indicação de que sim é o sucesso que faz em um teatro paulista a produção "nacional" de $A$ bela e a fera: teatro infantil para adultos!

Não vemos, entretanto, paradoxo nenhum no fato de que ainda hoje, apesar da contra-revolução, os mais relevantes atores do cinema americano, a cujo trabalho temos acesso, tenham sido todos aprendizes dos discípulos americanos de Stanislavski. Para ficar em poucos exemplos: Anne Bancroft, Al Pacino, Geraldine Page, Harvey Keitel, Dustin Hoffman...

Referências bibliográficas

ADLER, Stella. Ibsen, Strindberg e Tchekhop. Rio de Janeiro: Bertrand Brasil, 2002.

ADLER, Stella. Técnica da representação teatral. Rio de Janeiro: Civilização Brasileira, 2002.

CLURMAN, Harold. The Fervent years. Nova York: Harcourt, 2a . ed., 1975.

EDWARDS, Christine. The Stanislavski Heritage. Nova York: New York University Press, 1965.

FERGUSSON, Francis. The idea of a theater. Princeton: Princeton University Press, $2^{\mathrm{a}}$. ed., 1972.

FLANAGAN, Hallie. Schifting scenes. Nova York: Arno Press. $3^{a}$. ed., 1979.

GUINSBURG, J. Stanislavski, Meierhold \& Cia. São Paulo: Perspectiva, 2001.

HETHMON, Robert H. El método del Actors' Studio. Caracas: Fundamentos, $4^{\text {a }}$. ed., 1981.

KAZAN, Elia. A life. Nova York: Knopf, 1988.

LEWIS, Robert. Método ou loucura. Rio de Janeiro: Tempo Brasileiro, $2^{\text {a }}$. ed., 1982.

SMITH, Wendy. Real life drama - The Group Theatre and America, 1931-1940. Nova York: Grove Weidenfeld, 1990.

STRASBERG, Lee. Um sonho de paixão. Rio de Janeiro: Civilização Brasileira, 1990.

TCHEKHOV, Michael. Para o ator. São Paulo: Martins Fontes, 1986.

Iná Camargo Costa é professora associada do Departamento de Teoria Literária e Literatura Comparada da FFLCH-USP e autora de Panorama do Rio Vermelho - Ensaios sobre o teatro americano moderno (São Paulo: Nankin, 2001). 